\title{
Bilinguals' twisted tongues: Frequency lag or interference?
}

\author{
Chuchu Li ${ }^{1}$ - Matthew Goldrick ${ }^{2}$ Tamar H. Gollan ${ }^{1}$
}

Published online: 6 March 2017

(C) Psychonomic Society, Inc. 2017

\begin{abstract}
Though bilinguals know many more words than monolinguals, within each language bilinguals exhibit some processing disadvantages, extending to sublexical processes specifying the sound structure of words (Gollan \& Goldrick, Cognition, 125(3), 491-497, 2012). This study investigated the source of this bilingual disadvantage. Spanish-English bilinguals, Mandarin-English bilinguals, and English monolinguals repeated tongue twisters composed of English nonwords. Twister materials were made up of sound sequences that are unique to the English language (nonoverlapping) or sound sequences that are highly similar - yet phonetically distinct - in the two languages for the bilingual groups (overlapping). If bilingual disadvantages in tongue-twister production result from competition between phonetic representations in their two languages, bilinguals should have more difficulty selecting an intended target when similar sounds are activated in the overlapping sound sequences. Alternatively, if bilingual disadvantages reflect the relatively reduced frequency of use of sound sequences, bilinguals should have greater difficulty in the nonoverlapping condition (as the elements of such sound sequences are limited to a single language). Consistent with the frequency-lag account, but not the competition account, both Spanish-English and Mandarin-English bilinguals were disadvantaged in tonguetwister production only when producing twisters with nonoverlapping sound sequences. Thus, the bilingual
\end{abstract}

Chuchu Li

ch1441@ucsd.edu

1 Department of Psychiatry, University of California, San Diego, 9500 Gilman Drive, La Jolla, CA 92093-0948, USA

2 Northwestern University, Evanston, IL, USA disadvantage in tongue-twister production likely reflects reduced frequency of use of sound sequences specific to each language.

Keywords Bilingualism · Tongue twister · Speech error . Phonological processing

Though bilinguals are not obviously different from monolinguals when they speak in a single language, carefully controlled laboratory studies reveal subtle but significant linguistic processing disadvantages for bilinguals compared with monolinguals (see Bialystok, 2009, for review). Bilingual disadvantages have been found in a variety of different tasks, even when tested exclusively in their dominant language, including smaller vocabulary size (Oller \& Eilers, 2002), reduced verbal fluency (Gollan, Montoya, \& Werner, 2002), slower response times in picture naming (Gollan, Montoya, Cera, \& Sandoval, 2008), and more tip-of-the-tongue states (i.e., TOTs, in which speakers temporarily fail to retrieve a well-known word; e.g., Gollan \& Silverberg, 2001; Pyers, Gollan, \& Emmorey, 2009).

Recent evidence suggests that bilinguals also have more difficulty processing sublexical representations. In contrast to lexical representations, which refer to whole words, sublexical representations correspond to parts of words such as segments. The word $d o g$ has a single lexical representation, but at the sublexical level is associated with multiple elements (e.g., the three segments/d//ad//g/). There is no lexical representation for the nonword wug, but speakers access three segments $(/ \mathrm{w} /, / /$, and $/ \mathrm{g} /)$ at the sublexical level when they produce this nonword. Bilinguals have been shown to be disadvantaged relative to monolinguals in nonword repetition (Gibson et al., 2015; Summers, Bohman, Gillam, Peña, \& Bedore, 2010), and in repeating both word and nonword 
tongue twisters (Gollan \& Goldrick, 2012). Adopting the tongue-twister paradigm, a tool for inducing sound-based speech errors (Wilshire, 1998, 1999), Gollan and Goldrick (2012) instructed Spanish-English bilinguals, MandarinEnglish bilinguals, and English-speaking monolinguals to repeat English sound sequences made of real words (e.g., dirt, bus, boot, dose) or nonwords (e.g., deat, bock, dote, bart). Although bilinguals in Gollan and Goldrick (2012) had acquired English at an early age, were highly proficient in the target language, and were fully immersed in an Englishmajority culture, they still produced significantly more errors during tongue-twister production than English speaking monolinguals did. Additionally, Spanish-English bilinguals were most disadvantaged for nonword twister production, and Mandarin-English bilinguals were equally disadvantaged for nonword and word twister production. Thus, the bilingual disadvantage in twister production could not be attributed to lexical processing deficits; if anything, the disadvantage was enhanced without lexical support (as nonwords lack lexical representations), suggesting that it arises at a sublexical processing level that specifies sound structure. Though these results suggested that the bilingual disadvantage in tonguetwister production arises at the sublexical level, the mechanism of the disadvantage remains unclear. In this study, we consider the source of these sublexical processing difficulties in light of two explanations that have been widely considered to account for bilingual disadvantages in verbal tasks: language competition and frequency lag.

\section{Competition between languages}

On one view, bilinguals are disadvantaged because the intention to speak activates representations in both languages, and this coactivation creates greater competition for selection relative to that faced by monolinguals (Green, 1998; Kroll, Bobb, Misra, \& Guo, 2008). Supporting this interference hypothesis, considerable evidence suggests that even when bilinguals intend to speak in just one language, the nontarget language is nevertheless activated automatically - and competes with the target language. For example, Hermans, Bongaerts, De Bot, and Schreuder (1998) found that DutchEnglish bilinguals took longer to name the picture in English (e.g., mountain; "berg" in Dutch) when it appeared with a Dutch word phonologically related to the target's translation (e.g., berm; "verge" in English) than when it was accompanied by a control (e.g., kaars; "candle" in English; referred to as phonotranslation interference). This observation has been replicated in Spanish-Catalan bilinguals as well (Costa, Colomé, Gómez, \& Sebastián-Gallés, 2003; but see Costa, Miozzo, \& Caramazza, 1999, who showed significant facilitation when the picture was accompanied by a translation equivalent). Furthermore, many studies have suggested that bilinguals sometimes produce words in a language they did not intend to speak (Gollan, Sandoval, \& Salmon, 2011; Poulisse, 1999), and language mixing and switching often impairs production of the dominant language significantly more than the nondominant language (Gollan, Schotter, Gomez, Murillo, \& Rayner, 2014; Guo, Liu, Misra, \& Kroll, 2011; Kroll et al., 2008; Philipp, Gade, \& Koch, 2007; Philipp \& Koch, 2009).

Language competition also occurs at the phonetic level (Amengual, 2012; Goldrick, Runnqvist, \& Costa, 2014). For sounds that are phonologically similar, the phonetic systems of the two languages will interact so that bilinguals' production of these sounds are different from monolinguals of either language (Flege, 1987, 1991, 1995, 2002; MacKay, Flege, Piske, \& Schirru, 2001). For example, voice-onset time (VOT) refers to the time between the release of the consonant's constriction and the onset of periodicity signaling modal vocal-fold vibration. Many languages contrast voiced and voiceless consonant contrasts using VOTs, but do so in different ways. For instance, in Spanish this contrast is realized by negative versus short positive VOT (i.e., vibration occurs first vs. constriction release occurs first). While English has a similar contrast, it is realized differently — by a short versus long positive VOT (Lisker \& Abramson, 1964). As a result, when speaking English, Spanish-English bilinguals tended to produce shorter and more prevoiced VOTs than English monolinguals (Flege, 1991). This effect is not simply due to mislearning English sounds, as the effect is magnified when producing an English word after having recently produced a Spanish word (Balukas \& Koops, 2015; Goldrick et al., 2014; Olson, 2013). Interestingly, these effects of cross-language interference are enhanced for lexical items that induce strong cross-linguistic activation - cognates (translation equivalents that are similar; e.g., the Spanish word for tiger is tigre). Amengual (2012) found that in cognates, Spanish-English bilinguals produced Spanish voiceless stops with longer VOTs (i.e., more English-like) than they do when producing noncognates (see Jacobs, Fricke, \& Kroll, 2015, for complementary effects in English learners of Spanish). These studies suggest that interference between languages arises at the phonetic level during bilingual speech production, particularly when the nontarget language is strongly activated (e.g., producing cognates or recent production in the nontarget language). In such contexts, bilinguals tend to produce sounds with phonetic properties similar to that of the nontarget language.

Although bilinguals sometimes process cognates more easily than noncognates (e.g., Costa, Caramazza, \& SebastiánGallés, 2000; Gollan \& Acenas, 2004; Hoshino \& Kroll, 2008), these effects likely reflect lexical-level facilitation effects, which could not possibly arise when bilinguals process nonwords. Additionally, even with lexical-level support, cognates do not always elicit facilitation effects and in some cases 
instead elicit interference effects. For example, interference can arise when cognates are written similarly but pronounced differently across languages (Schwartz, Kroll, \& Diaz, 2007). Interference may also occur in a language-switching context when reading aloud written cognate words (Filippi, Karaminis, \& Thomas, 2014), or sometimes in picture naming (see English-dominant bilinguals in Broersma, Carter, \& Acheson, 2016; but see Christoffels, Firk, \& Schiller, 2007, and Verhoef, Roelofs, \& Chwilla, 2009) for the opposite results, i.e., consistent faster naming latency in cognates than noncogantes). Finally, interference has also been found for typed translation of written words, probably due to language competition at the orthographic level (Muscalu, 2007). If such competition effects can arise even with lexical-level support, they might well be considerably stronger when crosslanguage overlap arises at a sublexical level, specifically when bilinguals must produce subtle language-specific differences without lexical support. Thus, during tongue-twister production, between-language competition effects for nonwords with overlapping sounds might be particularly strong.

\section{Frequency lag}

An alternative explanation is that bilingual disadvantages arise because of a frequency lag (Gollan, Slattery, et al., 2011; a.k.a. weaker links, Gollan et al., 2008), an emergent property of bilingual language use. On this view, bilinguals have more difficulty with lexical access because they speak each of their languages relatively less frequently than monolinguals. Because frequency has robust effects on lexical accessibility, this leads to relative difficulty in accessing lexical items (Gollan \& Acenas, 2004; Gollan et al., 2008; Gollan, Slattery, et al., 2011). Consistent with this view, bilinguals name pictures more slowly than monolinguals, but especially if those pictures have low-frequency names (Gollan et al., 2008; Gollan, Slattery, et al., 2011; Ivanova \& Costa, 2008). Note that although frequency lag and notions of competition between languages are sometimes mutually compatible hypotheses (see Runnqvist, Strijkers, Sadat, \& Costa, 2011, for a review), some aspects of bilingual performance can only be explained by one or the other account (for discussion, see Kroll \& Gollan, 2014).

\section{The current study}

This study aimed to address the source of bilingual disadvantages at the sublexical level by asking bilinguals to repeat two different types of English nonword tongue twisters (i.e., sound sequences that are not real English words, but consist of sounds that can be found in English and follow the phonotactic constraints of English). To distinguish between the frequency-lag and interference hypotheses, we manipulated whether the twisters consisted of overlapping sound sequences (e.g., /puni/) that can be found both in English and the other language spoken by the bilinguals tested here (Spanish or Mandarin), or nonoverlapping sound sequences (e.g., /spæv/), that can be found in English, but not in the bilinguals' other language. (Note that the nonword materials used in our previous work (Gollan \& Goldrick, 2012) are an uncontrolled mixture of these sequence types.)

If the bilingual disadvantage in twister production is caused by cross-language interference at the level of sublexical retrieval, it could result from competition from coactivated language-specific sound-structure representations. Again, such interference effects have been found even in tasks conducted entirely in a monolingual context (e.g., Amengual, 2012). In such cases, similar, but phonetically distinct, language-specific representations disrupted the articulation of speech sounds. In this study, such competition would be possible for twisters with overlapping sound sequences, but not for twisters with nonoverlapping sound sequences. For example, the initial sound of the nonword $/ \mathrm{puni} /, / \mathrm{p} /$, could be pronounced with long VOT (i.e. English-like) or short VOT (i.e., Spanish-like). If representations of both sounds are activated in Spanish-English bilinguals, competition may occur. In contrast, because the sound sequences in the nonoverlapping condition are unique to English, the absence of highly similar forms across the two languages would prevent or reduce coactivation, allowing bilinguals to produce tongue twisters as accurately as monolinguals.

Conversely, if the bilingual disadvantage in twister production is caused by frequency lag, the opposite pattern should be found. Bilinguals will have had more cumulative practice producing overlapping than nonoverlapping sound sequences because the shared elements of cross-linguistically similar sounds would be produced in both languages. Given that frequent exposure facilitates processing, this will result in better performance on tongue twisters with overlapping sound sequences and worse performance on lower frequency, nonoverlapping sequences. For example, in the overlapping sound sequence /puni/, although the $/ \mathrm{p} /$ is pronounced slightly differently across languages (long vs. short VOT in English vs. Spanish), the frequency of this segment type is upped by production in both languages. As a result, pronouncing this type of sound is easier pronouncing the /sp/ sequence, /æ/ sound, or $/ \mathrm{v} /$ sound in the nonoverlapping sound sequence/spæv/, given that the all the three sound sequences (i.e., /sp/, /æ/, and /v/) are absent in Spanish. One might think production of individual sounds should not exhibit frequency effects, because all sounds would be used very frequently and therefore at maximum levels of proficiency. However, low-frequency segments elicit more speech errors than high-frequency segments do (Goldrick \& Rapp, 2007; Kupin, 1982). Such effects arise 
independent of the phonetic complexity of the sound sequences. The same sound can elicit different error rates depending on experiment-specific frequency distributions (Goldrick \& Larson, 2008). Thus, the fact that sound sequences unique to English are practiced less frequently by bilinguals than they are by monolinguals should lead bilinguals to have greater processing difficulty relative to sound sequences found in both languages.

\section{Method}

\section{Participants}

Ninety-six undergraduates at the University of California, San Diego, in each of three language groups (32 Spanish-English bilinguals, 32 Mandarin-English bilinguals, and 32 Englishspeaking monolinguals) participated for course credit. Table 1 shows self-reported participant characteristics and MINT (a Multilingual Naming Test) in English, and for bilinguals also in Spanish or Mandarin (the bilinguals' native language). Most participants in the two bilingual groups were Englishdominant (higher MINT scores in English vs. native language; 29 Spanish-English and 23 Mandarin-English). Both bilingual groups reported acquiring English later, lower self-rated
English proficiency, and had significantly lower English MINT scores than monolinguals.

\section{Materials and procedure}

Forty-eight tongue twisters composed of English nonsense words were designed. Nonwords in each tongue twister were identical except for the stop consonants in word-initial onsets, which contrasted in place of articulation. In the overlapping condition, each of the 24 tongue twisters consisted of four nonsense words with a CVCV (consonant-vowel-consonant-vowel) structure (e.g., tuni, puni, puni, tuni). In each nonsense word, the initial consonant was $/ \mathrm{t} /, / \mathrm{p} /$, or $/ \mathrm{k} /$, the second consonant $/ \mathrm{m} /$ or $/ \mathrm{n} /$, vowels were $/ \mathrm{u} /$ or $/ \mathrm{i} /$. All these sounds occur in English, Spanish, and Mandarin, and all the $\mathrm{CV}$ syllables can be found in all three languages as well. In the nonoverlapping condition, each of the 24 tongue twisters also had four nonsense words, but with CCVC structure (e.g., stave, spaev, spaev, staev). For each of these, the initial consonant was $/ \mathrm{s} /$, the second was $/ \mathrm{t} /, / \mathrm{p} /$, or $/ \mathrm{k} /$. The final consonant was $/ \mathrm{v} /$ or $/ \mathrm{y} /$, and the vowel was either $/ æ /$ or $/ /$. These initial consonant clusters do not occur in Mandarin or Spanish, while $/ \mathrm{v} /$ and $/ \mathrm{y} /$ as final consonants do not occur in Spanish. For vowels, /æ/ and / / do not occur in Spanish and occur only in restricted phonological environments in Mandarin.

Table 1 Means and standard deviations of participant characteristics

\begin{tabular}{|c|c|c|c|c|c|c|c|c|c|}
\hline & \multicolumn{2}{|c|}{$\begin{array}{l}\text { Spanish- } \\
\text { English }\end{array}$} & \multicolumn{2}{|c|}{$\begin{array}{l}\text { Mandarin- } \\
\text { English }\end{array}$} & \multicolumn{2}{|c|}{ Monolinguals } & \multirow{2}{*}{$\begin{array}{l}\text { Spanish-English } \\
\text { vs. } \\
\text { Monolinguals }\end{array}$} & \multirow{2}{*}{$\begin{array}{l}\text { Mandarin-English } \\
\text { vs. } \\
\text { Monolinguals }\end{array}$} & \multirow{2}{*}{$\begin{array}{l}\text { Spanish-English } \\
\text { vs. } \\
\text { Mandarin-English }\end{array}$} \\
\hline & $M$ & $S D$ & $M$ & $S D$ & $M$ & $S D$ & & & \\
\hline Age & 20.4 & 2.5 & 20.1 & 1.4 & 20.3 & 1.6 & & & \\
\hline Age of Acquisition of English & 3.8 & 2.8 & 4.0 & 3.4 & 0.5 & 1.2 & $* * *$ & $* * *$ & \\
\hline Self-rated spoken English proficiency ${ }^{\mathrm{a}}$ & 6.5 & 0.7 & 6.5 & 0.8 & 6.8 & 0.8 & $*$ & $*$ & \\
\hline Percentage of English use during childhood & 52.5 & 16.5 & 49.6 & 21.8 & 94.5 & 8.8 & $* * *$ & $* * *$ & \\
\hline Current percentage of English use & 78.8 & 20.1 & 81 & 19.5 & 98 & 5.9 & $* * *$ & $* * *$ & \\
\hline Primary caregiver English proficiency ${ }^{\mathrm{a}}$ & 3.6 & 1.8 & 4.6 & 1.5 & 6.4 & 1 & $* * *$ & $* * *$ & $*$ \\
\hline Secondary caregiver English proficiency ${ }^{a}$ & 4.0 & 2.2 & 4.7 & 1.6 & 6.2 & 1.3 & $* * *$ & $* * *$ & \\
\hline $\begin{array}{l}\text { Primary caregiver education level } \\
\text { (years of education) }\end{array}$ & 10.9 & 4.6 & 16 & 3.9 & 15.9 & 3.5 & $* * *$ & & $* * *$ \\
\hline $\begin{array}{l}\text { Secondary caregiver education level } \\
\text { (years of education) }\end{array}$ & 11.2 & 4.6 & 15 & 4.6 & 15.7 & 3.4 & $* * *$ & & $* * *$ \\
\hline $\begin{array}{l}\text { Years lived in non-English-speaking } \\
\text { country }\end{array}$ & 1.6 & 3.6 & 6.5 & 6.7 & 0.2 & 0.6 & $*$ & $* * *$ & $* * *$ \\
\hline MINT score in English ${ }^{\mathrm{b}}$ & 60.2 & 3.8 & 60.1 & 7.6 & 65.0 & 2.0 & $* * *$ & $* * *$ & \\
\hline MINT score in other language $\mathrm{e}^{\mathrm{b}}$ & 48.3 & 7.9 & 45.6 & 12.6 & - & - & & & \\
\hline \multicolumn{10}{|c|}{ For all comparisons not marked with $*$ or $* * * p>.14$} \\
\hline \multicolumn{10}{|l|}{$*$ Significant difference at $p<.05$ level } \\
\hline \multicolumn{10}{|l|}{$* * *$ Significant difference at $p<.001$ level } \\
\hline
\end{tabular}


Note that phonological structures that are less commonly found across languages also tend to also be less frequent within a language (see Goldrick \& Larson, 2008, for discussion). This holds true for our tongue twisters. Using word position-specific counts from Baayen, Piepenbrock, and Gulikers (1995), the mean frequency of syllables in our overlapping tongue twisters is $3,309 /$ million versus 8 /million for syllables in our nonoverlapping twisters. The nonoverlapping syllables are therefore predicted to be more difficult than overlapping syllables for both monolingual and bilingual speakers. Critically, the frequency-lag account predicts that this frequency effect will be significantly larger for the bilingual than for the monolingual speakers.

Stimuli were presented using PsyScope $\mathrm{X}$ software (Cohen, MacWhinney, Flatt, \& Provost, 1993, http://www. psy.ck.sissa.it) on an iMac 7 computer with a 20-inch color monitor. For each trial, the four nonsense words were presented in written form in the center of the screen. Participants were instructed in English to read aloud the four nonsense words sequentially 4 times paced by a 100 BPM metronome. The 24 twisters in each condition were evenly divided between ABBA (e.g., tuni, puni, puni, tuni) and ABAB (e.g., tuni, puni, tuni, puni), and the order of the two conditions was counterbalanced between participants.

\section{Results}

Productions were transcribed by two annotators. Reliability was assessed using 4,008 nonsense words across six participants (three monolingual, three bilingual). Agreement between the transcribers was $97 \%$.

The annotators identified a total of 6,498 errors. Figure 1 shows the average number of errors that each participant made within each trial (i.e., the total number of additions, substitution, segmental, or syllable deletions produced by a participant for each tongue-twister sequence). The total counts of errors were analyzed using mixed-effect negative binomial regressions (using the R package lme4; Bates, Maechler, Bolker, \& Walker, 2015). These models are appropriate for count data such as number of errors, relative to alternatives such as linear regressions (which analyze continuous variables) and logistic regressions (used to model proportional data). Separate regressions compared Spanish-English bilinguals to monolinguals and Mandarin-English bilinguals to monolinguals. Contrastcoded fixed effects included language group (bilingual vs. monolingual), condition (overlapping vs. nonoverlapping), and the interaction of these factors. Subject and twister/trial were served as two random intercepts (models with random slopes failed to converge). The significance of each fixed effect was assessed via likelihood ratio tests (Barr, Levy, Scheepers, \& Tily, 2013).

Like many statistical models, our regressions assume that events are independent. This assumption may be particularly problematic within each trial; if an error occurs on one syllable within a particular tongue twister, it may increase the probability that errors will occur on subsequent syllables (violating independence). We therefore also used logistic mixed-effects regressions (Jaeger, 2008) to analyze accuracy at the level of whole trials (i.e., whether the trial was completely correct vs. contained one or more, that is, any number of errors; see Fig. 2). The only difference in model structure relative to the first analysis was the addition of correlated random slopes. Note that this analysis has reduced power relative to the first analysis, as it obscures differences in degree of difficulty within a trial.

\section{Spanish-English bilinguals}

In the negative binomial regressions, Spanish-English bilinguals produced significantly more errors than monolinguals overall (mean 1.91 vs. 1.07 errors); $\beta=.51 ; S E \beta=.23 ; \chi^{2}(1)$

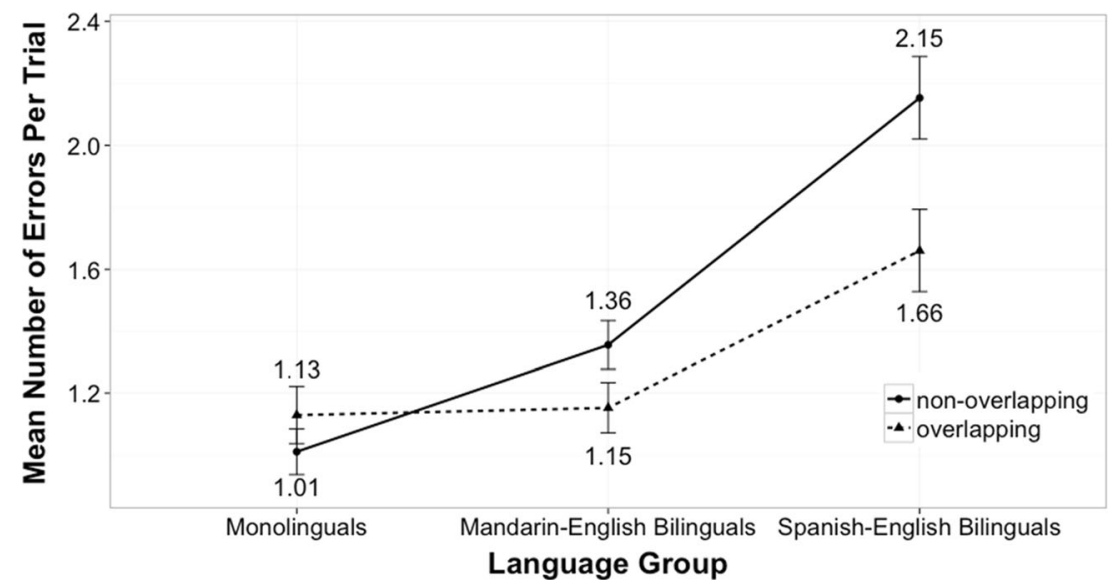

Fig. 1 Mean number of errors within each trial for each condition and language group 


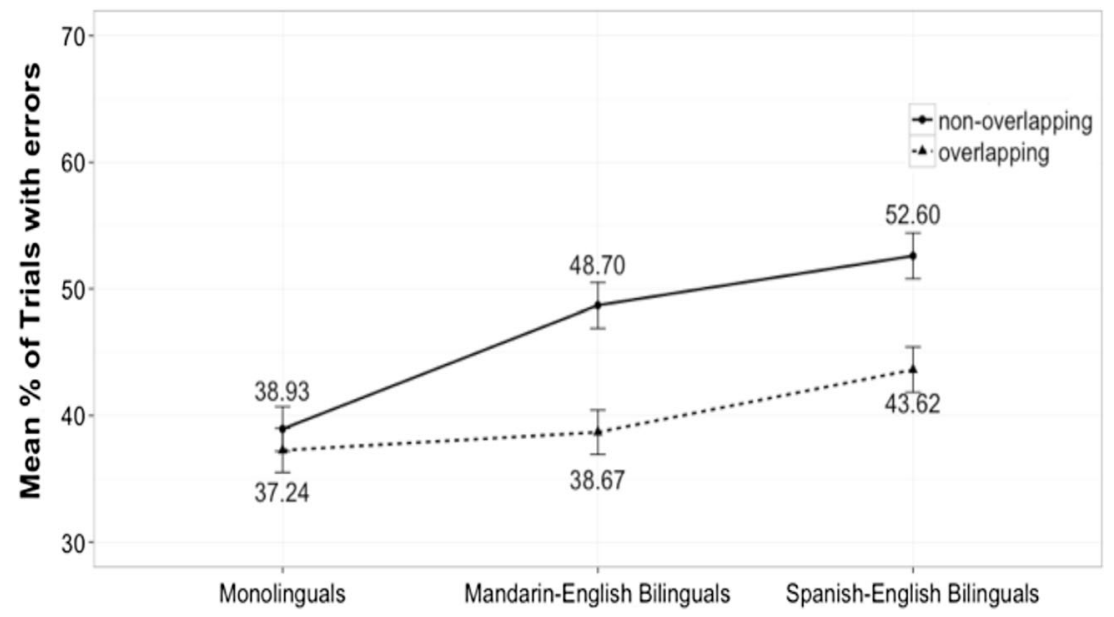

Fig. 2 Mean percentage of trials with errors for each condition and language group

$=4.55, p=.033$. While there was no overall effect of overlap (mean 1.58 errors for nonoverlapping vs. 1.39 errors for overlapping); $\beta=-.09 ; S E \beta=.13 ; \chi^{2}(1)=.51, p=.477$, there was a significant interaction between participant group and overlap, $\beta=-.34 ; S E \beta=.12 ; \chi^{2}(1)=7.87, p=.005$. Consistent with the predictions of the frequency-lag account, bilinguals were disadvantaged only for nonoverlapping twisters. In follow-up regressions within each group, bilinguals produced significantly more errors than monolinguals in the nonoverlapping condition (mean 2.15 vs. 1.01 errors); $\beta=.71 ; S E \beta=$ $.24 ; \chi^{2}(1)=7.91, p=.005$, while the two groups performed similarly in the overlapping condition (mean 1.66 vs. 1.13 errors); $\beta=.32 ; S E \beta=.26 ; \chi^{2}(1)=1.47, p=.225$. In addition, bilinguals produced more errors in the nonoverlapping condition than the overlapping condition (mean 2.15 vs. 1.66 errors); $\beta=-.27 ; S E \beta=.13 ; \chi^{2}(1)=3.89, p=.048$, while monolinguals performed similarly in the two conditions (mean 1.01 vs. 1.13 errors); $\beta=.076 ; S E \beta=.15 ; \chi^{2}(1)=$ $.25, p=.614$. The logistic mixed-effects regressions with triallevel accuracy as the dependent variable showed similar results, except that the overall bilingual disadvantage (i.e., the main effect of language group) was only marginally significant, $\beta=.52 ; S E \beta=.27 ; \chi^{2}(1)=3.5, p=.062$.

To consider if the bilingual disadvantage in twister production might be attributable to the difficulty of producing tongue twisters in a nondominant language, we asked if similar results are found when excluding all bilinguals whose MINT score was higher in Spanish than in English. When we repeated our analysis including only the 29 English-dominant bilinguals, the results were qualitatively similar. Critically, the interaction between language group and condition was significant, $\beta=$ -.36; $S E \beta=.13 ; \chi^{2}(1)=8.33, p=.004$, and follow-up comparisons showed that English-dominant bilinguals produced more errors than monolinguals in the nonoverlapping condition (mean 2.23 vs. 1.01 errors); $\beta=.74 ; S E \beta=.25 ; \chi^{2}(1)=$ $8.25, p=.004$, but not in the overlapping condition (mean
1.68 vs. 1.13 errors); $\beta=.33 ; S E \beta=.27 ; \chi^{2}(1)=1.46, p=$ .227 , and English-dominant bilinguals produced more errors in the nonoverlapping than in the overlapping conditions (mean 2.23 vs. 1.68 errors); $\beta=-.29 ; S E \beta=.14 ; \chi^{2}(1)=$ $4.28, p=.039$. Similar effects were found in logistic mixedeffects regressions examining trial-level accuracy.

\section{Mandarin-English bilinguals}

In the negative binomial regressions, bilinguals tended to produce more errors than monolinguals overall, but this difference was just marginally significant (mean 1.25 vs. 1.07 errors); $\beta=.33 ; S E \beta=.19 ; \chi^{2}(1)=3.15, p=.076$. As reported above, overall, speakers produced equivalent numbers of errors in the overlapping and nonoverlapping conditions (mean 1.18 errors for nonoverlapping vs. 1.14 errors for overlapping); $\beta=-.060 ; S E \beta=.12 ; \chi^{2}(1)=.25, p=.620$, but there was a significant interaction between participant group and condition, $\beta=-.31 ; S E \beta=.13 ; \chi^{2}(1)=6.09, p=.014$. As found for Spanish-English bilinguals, and as predicted by the frequency-lag account, Mandarin-English bilinguals were more disadvantaged for nonoverlapping than for overlapping twisters. In follow-up regressions within each condition, bilinguals produced significantly more errors than the monolinguals in the nonoverlapping condition (mean 1.36 vs. 1.01 errors); $\beta=.50 ; S E \beta=.20 ; \chi^{2}(1)=5.93, p=.015$, while the two groups performed similarly in the overlapping condition (mean 1.15 vs. 1.13 errors); $\beta=.14 ; S E \beta=.23 ; \chi^{2}(1)=$ $.35, p=.554$. In addition, bilinguals produced marginally ( $\beta=$ - .23; $\left.S E \beta=.13 ; \chi^{2}(1)=3.01, p=.083\right)$ more errors in the nonoverlapping than the overlapping conditions (mean 1.36 vs. 1.15 errors), whereas monolinguals exhibited no such trends (i.e., they performed similarly in the two conditions; mean 1.01 vs. 1.13 errors); $\beta=.076 ; S E \beta=.15 ; \chi^{2}(1)=$ $.25, p=.614$. Similar results were found in logistic mixedeffects regressions, except that the interaction between 
language group and condition was only marginally significant, $\beta=-.42 ; S E \beta=.22 ; \chi^{2}(1)=3.5, p=.060$.

Fewer of the Mandarin-English bilinguals were English dominant (relative to the Spanish-English bilinguals). Analyses including only the 23 English-dominant Mandarin-English bilinguals revealed qualitatively similar results. Critically, the interaction between language group and condition was significant, $\beta=-.27 ; S E \beta=.16 ; \chi^{2}(1)=3.90, p$ $=.048$, in the negative binomial regressions. Possibly due to the reduction in power, the follow-up comparison of the two language groups within the nonoverlapping condition was just marginally significant, with English-dominant MandarinEnglish bilinguals producing more errors than monolinguals (mean 1.31 vs. 1.01 errors); $\beta=.43 ; S E \beta=.23 ; \chi^{2}(1)=3.36$, $p=.067$. Additionally, the interaction between participant group and condition trended in the right direction in the logistic mixed-effects regressions, but was not significant, $\beta=-.39$; $S E \beta=.24 ; \chi^{2}(1)=2.57, p=.109$.

\section{Vocabulary matched bilinguals and monolinguals}

To investigate whether the bilingual disadvantage is a result of lower English proficiency, we kept all the 32 monolinguals and selected a group of 31 bilinguals (18 Mandarin-English bilinguals, 13 Spanish-English bilinguals) whose English MINT scores $(M=64.5, S D=2.0)$ matched with 32 monolinguals' $(M=65, S D=2.0)$. Of interest, this vocabulary matched subgroup of bilinguals elicited a similar pattern of results; that is, the interaction between language background and tongue-twister type was significant, $\beta=-.39 ; S E \beta=.12$; $\chi^{2}(1)=10.1, p=.001$. The high-vocabulary bilinguals produced significantly more errors than monolinguals in the nonoverlapping condition (mean 1.80 errors vs. 1.01 errors); $\beta=$ $.57 ; S E \beta=.24 ; \chi^{2}(1)=5.51, p=.019$, but not in the overlapping condition (mean 1.38 vs. 1.13 errors); $\beta=.12 ; S E \beta=$ $.26 ; \chi^{2}(1)=.22, p=.640$, and the high-vocabulary bilinguals produced more errors in the nonoverlapping than the overlapping conditions (mean 1.80 errors vs. 1.38 errors); $\beta=-.30$; $S E \beta=.14 ; \chi^{2}(1)=4.40, p=.036$, while the monolinguals performed similarly in the two conditions (mean 1.01 vs. 1.13 errors; $\beta=.076 ; S E \beta=.15 ; \chi^{2}(1)=.25, p=.614$. The logistic mixed-effects regressions showed similar results.

\section{Error types}

Even though our analyses imply similar mechanisms underlying the bilingual disadvantage in Spanish-English and Mandarin-English bilinguals (i.e., both bilingual groups were more disadvantaged with nonoverlapping than with overlapping twisters), it is possible that further investigation will reveal subtle differences between groups. Figure 3 illustrates an exploratory division of our data into error types, including segment substitution (e.g., saying spaev for skaev), syllable deletion (e.g., failing to say the whole syllable skaev), segment deletion (e.g., saying kaev for skaev), and addition (e.g., saying skaevi or skskaev for skaev).

We did not conduct statistical analysis of each error type, given that power is greatly reduced (because of smaller numbers of observations and the need to correct for multiple comparisons). However, inspection of the figure suggests some striking differences that could be pursued in future work. The pattern we observed above (collapsing across error types) is a higher error rate for nonoverlapping versus overlapping sequences, with the difference largest for bilingual versus monolingual speakers. While deletions of individual segments follow this pattern for both groups of bilingual speakers, deletions of whole syllables suggest possible differences across groups; Spanish-English but not Mandarin-English show more syllable deletions for nonoverlapping versus overlapping sequences.

Segment substitutions show a quite unexpected pattern; the monolinguals and Spanish-English bilinguals show higher error rates on overlapping sequences. This could reflect distinct patterns of difficulty with overlapping versus nonoverlapping sequences; there may be differing opportunities for minor errors like substitutions versus majors distortions like whole-syllable deletion for these two types of twisters. When production of a nonoverlapping sequence is disrupted, the result may frequently be a severe distortion of the target forms, with major alterations to their phonological structure (i.e., deletions, or reductions of consonant clusters, and omitting entire syllables). This precludes the possibility of producing a substitution error. In contrast, when production of an overlapping twister is disrupted, the relative ease of processing might allow for the possibility of minor distortions of the target twister (i.e., substitution errors - which largely preserve the overall syllabic and prosodic structure of the twister).

What these descriptive analyses make clear is the need for future investigation of these patterns: further exploration of the differences in processing of these two different sequence types, and a more detailed examination of how different types of bilingual experience shape the structure of errors made during sublexical processing.

\section{Discussion}

This study compared two groups of bilinguals (SpanishEnglish bilinguals and Mandarin-English bilinguals) to English monolinguals in their ability to produce English nonword tongue twisters. The twisters either consisted of sound sequences and syllables that are found in both languages spoken by the bilinguals (overlapping) or that are unique to English (nonoverlapping). Both bilingual groups performed similarly to monolinguals in the overlapping condition, but produced significantly more errors than monolinguals in the 

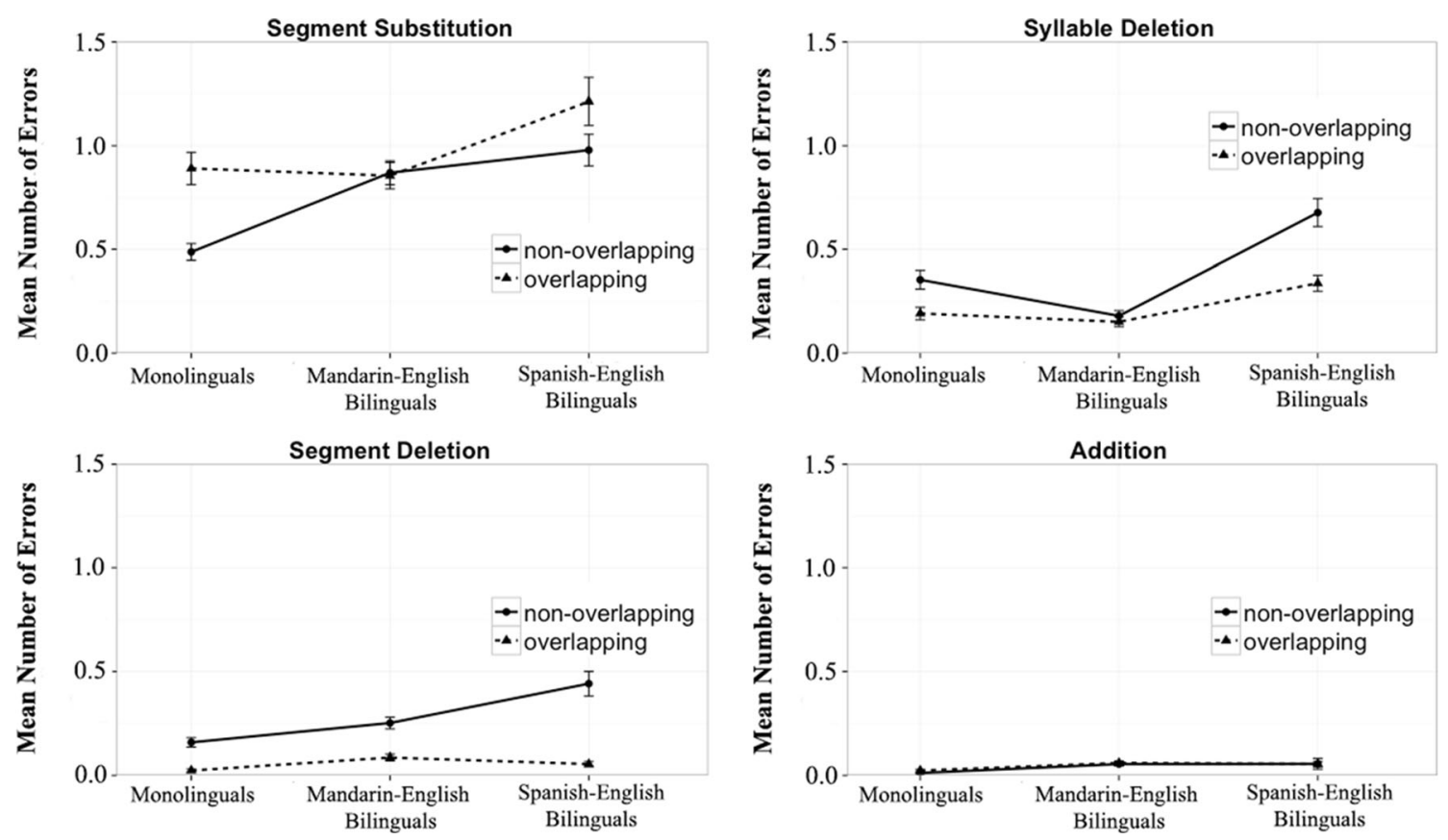

Fig. 3 Mean number of errors within each trial for each condition and language group according to error type

nonoverlapping condition. In addition, both bilingual groups, but not monolinguals, produced more errors in the nonoverlapping than in the overlapping condition. The results were consistent in both bilingual groups, suggesting that our findings were not an artifact of one population or the demographic features that are associated with each group. Instead, they provide reliable and broadly generalizable results that will likely apply to bilingual speakers of all language combinations. In addition, we showed that similar results were found when the analysis was restricted to English-dominant bilinguals, and even to vocabulary matched groups of bilinguals and monolinguals. This suggests that the bilingual disadvantage does not simply reflect relatively low English proficiency and is not an artifact of production in a nondominant language. Further investigation is needed to determine why vocabulary matching - which might eliminate any effects of frequency lag at the lexical level—did not also eliminate lag effects at the sublexical level.

This study replicated and extended the findings in Gollan and Goldrick (2012), which showed bilingual disadvantages at the sublexical level, but did not investigate the mechanism of these disadvantages. Our results suggest that the bilingual disadvantage in nonword tongue-twister production is not likely to be caused by between-language interference. Under this account, bilinguals should have shown the highest accuracy in the nonoverlapping condition, which would minimize cross-linguistic interference. Instead, the results are consistent with the frequency-lag account; nonoverlapping sound sequences are less practiced for bilinguals because they are used in one but not the other language spoken by bilinguals. Thus, their relatively low frequency appears to result in processing difficulty. Note that our results did not suggest that competition at the phonetic level never occurs. Instead, such competition may be more likely to arise in situations where there is uncertainty about which language will be used, such as a language-switching task (Goldrick et al., 2014), and further research is needed to reveal when competition between languages can arise at the phonetic level.

A further question that merits additional inquiry is why monolinguals did not exhibit robust differences between conditions in our study. Based on frequency lag, weaker effects of twister type should be found with monolinguals, as the nonoverlapping syllables have lower frequency in English than the overlapping syllables. However, monolingual performance may be too close to ceiling in our task to produce significant frequency effects. At faster speaking rates, which would elicit higher error rates, a more robust frequency effect should emerge for monolinguals (see Goldrick \& Larson, 2008 , in which monolinguals repeated tongue twisters at a rate of $210 \mathrm{BPM})$.

Another issue is why monolinguals and Mandarin-English bilinguals performed similarly in the overlapping condition while Spanish-English bilinguals made more errors than the other two groups (see Fig. 1). This could arise because the overlapping sequence does not occur exactly equally often for all the three groups - the critical comparison in this study is simply that overlapping sound sequences are more frequent than the nonoverlapping ones, not that they have a particular frequency level. It is also possible is that the considerable overlap in writing systems between English and Spanish could have allowed our written materials to induce a more bilingual mode (see Grosjean, 1994) in Spanish-English relative to 
Mandarin-English bilinguals. Alternatively, differences between groups might reflect other aspects of their exposure to and use of two languages. For example, Spanish has a much more prominent presence in the linguistic and cultural environment of San Diego than Mandarin; this (rather than orthography) may have led to a more bilingual mode for the Spanish-English versus Mandarin-English bilinguals.

Beyond frequency lag, difficulty with acquisition of two different and contrasting phonological systems (see Bosch \& Sebastián-Gallés, 2003; Werker, 2012 for simultaneous acquisition, and Best \& Tyler, 2007, for sequential acquisition) may also contribute to the bilingual disadvantage in sublexical processing. Like frequency lag, this account predicts a greater disadvantage for bilinguals with production of nonoverlapping twisters. Properties of one language can facilitate the acquisition of the other language for shared sounds (e.g., those founds in overlapping sound sequences). In contrast, acquiring unshared sounds is more difficult since they belong to two distinct phonological systems and do not allow for positive transfer between languages (e.g., those found in nonoverlapping sequences). Supporting this view, previous studies found that bilingual children have higher production accuracy for shared sounds compared to unshared sounds (Fabiano-Smith \& Goldstein, 2010). Note that the difficulty of acquisition account is different from an age of acquisition effect since acquiring two distinct phonological systems is more difficult than acquiring one, even for young language learners. It is difficult to differentiate the frequency lag and difficulty of acquisition accounts, as the factors underlying each account are highly correlated. As noted in the "Method" section, frequency within a language tends to correlate with frequency across languages. Unshared sounds are likely to be less frequent cross-linguistically, and therefore less frequent within a particular language; this general correlation presents a challenge to discriminating these accounts.

In summary, this study suggests the bilingual disadvantage in speech production at the sublexical level that specifies sound structure is likely due to frequency lag, or difficulty of acquisition of two distinct phonological systems, or both. Conversely, the bilingual disadvantage appears not to be due to difficulty with selecting between competing sound representations in each language and also not by lower proficiency or production in a nondominant language. Instead, bilinguals' increased production of tongue-twister errors appears to reflect reduced accessibility of sound structures unique to one of the bilinguals' two languages. The findings of this study imply that caution is needed when developing materials for future work with bilinguals, as overlapping sounds may cancel out bilinguals' disadvantages in some languageproduction tasks. More broadly, these results provide additional support for the view that sublexical processes are sensitive not only to the inherent articulatory complexity of different sound sequences but also to the relative frequency with which different speakers encounter them (Goldrick \& Larson, 2008).

Acknowledgements This research was supported by grants from the National Institute on Deafness and Other Communication Disorders (011492), the National Institute of Child Health and Human Development (050287; 077140; 079426; 051030), and the National Science Foundation (BCS0846147; BCS1457159). Any opinions, findings, and conclusions or recommendations expressed in this material are those of the authors and do not necessarily reflect the views of the NIH or NSF. We thank Mackenzie Young and Michael Blasingame for error coding.

\section{References}

Amengual, M. (2012). Interlingual influence in bilingual speech: Cognate status effect in a continuum of bilingualism. Bilingualism: Language and Cognition, 15(03), 517-530. doi:10.1017 /S1366728911000460

Baayen, R. H., Piepenbrock, R., \& Gulikers, L. (1995). The CELEX lexical database (Release 2): Linguistic data consortium. Philadelphia: University of Pennsylvania.

Balukas, C., \& Koops, C. (2015). Spanish-English bilingual voice onset time in spontaneous code-switching. International Journal of Bilingualism, 19(4), 423-443. doi:10.1177/1367006913516035

Barr, D. J., Levy, R., Scheepers, C., \& Tily, H. J. (2013). Random effects structure for confirmatory hypothesis testing: Keep it maximal. Journal of Memory and Language, 68(3). doi:10.1016/j. jml.2012.11.001

Bates, D., Maechler, M., Bolker, B., \& Walker, S. (2015). Fitting linear mixed-effects models using lme4. Journal of Statistical Software, 67(1), 1-48. doi:10.18637/jss.v067.i01

Best, C. T., \& Tyler, M. D. (2007). Nonnative and second-language speech perception: Commonalities and complementarities. In M. J. Munro \& O.-S. Bohn (Eds.), Second language speech learning: The role of language experience in speech perception and production (pp. 13-34). Amsterdam: John Benjamins.

Bialystok, E. (2009). Bilingualism: The good, the bad, and the indifferent. Bilingualism: Language and Cognition, 12(01), 3. doi:10.1017 /S1366728908003477

Bosch, L., \& Sebastián-Gallés, N. (2003). Simultaneous bilingualism and the perception of a language-specific vowel contrast in the first year of life. Language and Speech, 46(2/3), 217-243. doi:10.1177 /00238309030460020801

Broersma, M., Carter, D., \& Acheson, D. J. (2016). Cognate costs in bilingual speech production: Evidence from language switching. Frontiers in Psychology, 7, 1461. doi:10.3389/fpsyg.2016.01461

Christoffels, I. K., Firk, C., \& Schiller, N. O. (2007). Bilingual language control: An event-related brain potential study. Brain Research, 1147, 192-208.

Cohen, J. D., MacWhinney, B., Flatt, M., \& Provost, J. (1993). PsyScope: A new graphic interactive environment for designing psychology experiments. Behavioral Research Methods, Instruments, and Computers, 25(2), 257-271.

Costa, A., Caramazza, A., \& Sebastián-Gallés, N. (2000). The cognate facilitation effect: Implications for models of lexical access. Journal of Experimental Psychology: Learning, Memory, and Cognition, 26, 1283-1296.

Costa, A., Colomé, À., Gómez, O., \& Sebastián-Gallés, N. (2003). Another look at cross-language competition in bilingual speech production: Lexical and phonological factors. Bilingualism: Language and Cognition, 6(03), 167-179. doi:10.1017/S1366728903001111 
Costa, A., Miozzo, M., \& Caramazza, A. (1999). Lexical selection in bilinguals: Do words in the bilingual's two lexicons compete for selection? Journal of Memory and Language, 41(3), 365-397. doi:10.1006/jmla.1999.2651

Fabiano-Smith, L., \& Goldstein, B. A. (2010). Phonological acquisition in bilingual Spanish-English speaking children. Journal of Speech, Language, and Hearing Research, 53(1), 160-178.

Filippi, R., Karaminis, T., \& Thomas, M. S. (2014). Language switching in bilingual production: Empirical data and computational modelling. Bilingualism: Language and Cognition, 17(02), 294-315. doi:10.1017/S1366728913000485

Flege, J. E. (1987). The production of "new" and "similar" phones in a foreign language: Evidence for the effect of equivalence classification. Journal of Phonetics, 15(1), 47-65.

Flege, J. E. (1991). Age of learning affects the authenticity of voice-onset time (VOT) in stop consonants produced in a second language. Journal of the Acoustical Society of America, 89, 395-411.

Flege, J. E. (1995). Two procedures for training a novel second language phonetic contrast. Applied Psycholinguistics, 16, 425-442.

Flege, J. E. (2002). Interactions between the native and second-language phonetic systems. In P. Burmeister, T. Piske, \& A. Rohde (Eds.), An integrated view of language development: Papers in honor of Henning Wode (pp. 217-244). Trier: Wissenschaftlicher Verlag.

Gibson, T. A., Summers, C., Peña, E. D., Bedore, L. M., Gillam, R. B., \& Bohman, T. M. (2015). The role of phonological structure and experience in bilingual children's nonword repetition performance. Bilingualism: Language and Cognition, 18(03), 551-560. doi:10.1017/S1366728914000248

Goldrick, M., \& Larson, M. (2008). Phonotactic probability influences speech production. Cognition, 107(3), 1155-1164. doi:10.1016/j. cognition.2007.11.009

Goldrick, M., \& Rapp, B. (2007). Lexical and post-lexical phonological representations in spoken production. Cognition, 102(2), 219-260. doi:10.1016/j.cognition.2005.12.010

Goldrick, M., Runnqvist, E., \& Costa, A. (2014). Language switching makes pronunciation less nativelike. Psychological Science, 25(4), 1031-1036.

Gollan, T. H., \& Acenas, L.-A. R. (2004). What is a TOT? Cognate and translation effects on tip-of-the-tongue states in Spanish-English and tagalog-English bilinguals. Journal of Experimental Psychology: Learning, Memory, and Cognition, 30(1), 246-269. doi: $10.1037 / 0278-7393.30 .1 .246$

Gollan, T. H., \& Goldrick, M. (2012). Does bilingualism twist your tongue? Cognition, 125(3), 491-497. doi:10.1016/j.cognition.2012.08.002

Gollan, T. H., Montoya, R. I., Cera, C., \& Sandoval, T. C. (2008). More use almost always means a smaller frequency effect: Aging, bilin-

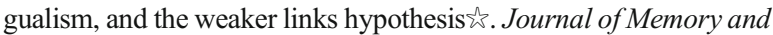
Language, 58(3), 787-814. doi:10.1016/j.jml.2007.07.001

Gollan, T. H., Montoya, R. I., \& Werner, G. A. (2002). Semantic and letter fluency in Spanish-English bilinguals. Neuropsychology, 16(4), 562-576. doi:10.1037/0894-4105.16.4.562

Gollan, T. H., Sandoval, T., \& Salmon, D. P. (2011). Cross-language intrusion errors in aging bilinguals reveal the link between executive control and language selection. Psychological Science, 22(9), 11551164. doi: $10.1177 / 0956797611417002$

Gollan, T. H., Schotter, E. R., Gomez, J., Murillo, M., \& Rayner, K. (2014). Multiple levels of bilingual language control evidence from language intrusions in reading aloud. Psychological Science, 25(2), 585-595. doi:10.1177/0956797613512661

Gollan, T. H., \& Silverberg, N. B. (2001). Tip-of-the-tongue states in Hebrew-English bilinguals. Bilingualism: Language and Cognition, 4(01), 63-83. doi:10.1017/S136672890100013X

Gollan, T. H., Slattery, T. J., Goldenberg, D., Van Assche, E., Duyck, W., \& Rayner, K. (2011). Frequency drives lexical access in reading but not in speaking: The frequency-lag hypothesis. Journal of Experimental Psychology: General, 140(2), 186-209. doi:10.1037/a0022256
Green, D. W. (1998). Mental control of the bilingual lexico-semantic system. Bilingualism: Language and Cognition, 1(02), 67-81. doi:10.1017/S1366728998000133

Grosjean, F. (1994). Individual bilingualism. In R. E. Asher \& J. M. Y. Simpson (Eds.), The encyclopedia of language and linguistics (pp. 1656-1660). Oxford: Pergamon Press.

Guo, T., Liu, H., Misra, M., \& Kroll, J. F. (2011). Local and global inhibition in bilingual word production: fMRI evidence from Chinese-English bilinguals. NeuroImage, 56(4), 2300-2309. doi:10.1016/j.neuroimage.2011.03.049

Hermans, D., Bongaerts, T., De Bot, K., \& Schreuder, R. (1998). Producing words in a foreign language: Can speakers prevent interference from their first language? Bilingualism: Language and Cognition, 1(03), 213-229.

Hoshino, N., \& Kroll, J. F. (2008). Cognate effects in picture naming: Does cross-language activation survive a change of script? Cognition, 106, 501-511.

Ivanova, I., \& Costa, A. (2008). Does bilingualism hamper lexical access in speech production? Acta Psychologica, 127(2), 277-288.

Jacobs, A., Fricke, M., \& Kroll, J. F. (2015). Cross-language activation begins during speech planning and extends into second language speech. Language Learning, 66, 324-353. doi:10.1111/lang.12148

Jaeger, T. F. (2008). Categorical data analysis: Away from ANOVAs (transformation or not) and towards logit mixed models. Journal of Memory and Language, 59(4), 434-446.

Kroll, J. F., Bobb, S. C., Misra, M., \& Guo, T. (2008). Language selection in bilingual speech: Evidence for inhibitory processes. Acta Psychologica, 128(3), 416-430. doi:10.1016/j.actpsy.2008.02.001

Kroll, J. F., \& Gollan, T. H. (2014). Speech planning in two languages: What bilinguals tell us about language production. In V. Ferreira, M. Goldrick, \& M. Miozzo (Eds.), The Oxford handbook of language production (pp. 165-181). Oxford: Oxford University Press. doi:10.1093/oxfordhb/9780199735471.013.001

Kupin, J. J. (1982). Tongue twisters as a source of information about speech production. Bloomington: Indiana University Linguistics Club.

Lisker, L., \& Abramson, A. S. (1964). A cross-language study of voicing in initial stops: Acoustical measurements. Word, 20(3), 384-422.

MacKay, I. R., Flege, J. E., Piske, T., \& Schirru, C. (2001). Category restructuring during second-language speech acquisition. The Journal of the Acoustical Society of America, 110(1), 516-528.

Muscalu, L. (2007). The role of phonological activation in bilinguals' orthographic realization of words (Unpublished doctoral dissertation, Claremont Graduate University, CA).

Oller, D. K., \& Eilers, R. E. (2002). Language and literacy in bilingual children. Bristol: Multilingual Matters.

Olson, D. J. (2013). Bilingual language switching and selection at the phonetic level: Asymmetrical transfer in VOT production. Journal of Phonetics, 41, 407-420.

Philipp, A. M., Gade, M., \& Koch, I. (2007). Inhibitory processes in language switching: Evidence from switching language-defined response sets. European Journal of Cognitive Psychology, 19(3), 395416. doi:10.1080/09541440600758812

Philipp, A. M., \& Koch, I. (2009). Inhibition in language switching: What is inhibited when switching between languages in naming tasks? Journal of Experimental Psychology: Learning, Memory, and Cognition, 35(5), 1187-1195. doi:10.1037/a0016376

Poulisse, N. (1999). Slips of the tongue: Speech errors in first and second language production. Amsterdam: John Benjamins.

Pyers, J. E., Gollan, T. H., \& Emmorey, K. (2009). Bimodal bilinguals reveal the source of tip-of-the-tongue states. Cognition, 112(2), 323 329. doi:10.1016/j.cognition.2009.04.007

Runnqvist, E., Strijkers, K., Sadat, J., \& Costa, A. (2011). On the temporal and functional origin of L2 disadvantages in speech production: A critical review. Frontiers in Psychology, 2, 379. doi:10.3389 /fpsyg.2011.00379 
Schwartz, A. I., Kroll, J. F., \& Diaz, M. (2007). Reading words in Spanish and English: Mapping orthography to phonology in two languages. Language \& Cognitive Processes, 22(1), 106-129. doi:10.1080 /01690960500463920

Summers, C., Bohman, T. M., Gillam, R. B., Peña, E. D., \& Bedore, L. M. (2010). Bilingual performance on nonword repetition in Spanish and English. International Journal of Language \& Communication Disorders, 45(4), 480-493. doi:10.3109/13682820903198058

Verhoef, K. M. W., Roelofs, A., \& Chwilla, D. J. (2009). Role of inhibition in language switching: Evidence from event-related brain potentials in overt picture naming. Cognition, 110, 8499.

Werker, J. (2012). Perceptual foundations of bilingual acquisition in infancy. Annals of the New York Academy of Sciences, 1251(1), 50 61. doi:10.1111/j.1749-6632.2012.06484.x

Wilshire, C. E. (1998). Serial order in phonological encoding: An exploration of the 'word onset effect' using laboratory-induced errors. Cognition, 68(2), 143-166. doi:10.1016/S0010-0277(98)00045-6

Wilshire, C. E. (1999). The "tongue twister" paradigm as a technique for studying phonological encoding. Language and Speech, 42(1), 5782. doi:10.1177/00238309990420010301 